\title{
Correlation of the Neck Circumference with Blood Pressure
}

\author{
Sarbada Makaju, ${ }^{1}$ Sonam Chaudhary, ${ }^{2}$ Munna Alam ${ }^{3}$ \\ ${ }^{1}$ Department of Anatomy, ${ }^{2}$ Department of Physiology, Manipal College of Medical Sciences, Pokhara, Nepal, \\ ${ }^{3}$ Department of Prosthodontics, Nepalese Army Institute of Health Sciences, Kathmandu, Nepal.
}

\begin{abstract}
Background: The growing epidemic of hypertension owing to physical inactivity and dietary modification is a global burden. The obesity which acts as a pre-disposing factor for blood pressure can be measured with neck circumference (NC) as well. Thus, the aim of this study is to find out the relation between the components of blood pressure and the neck circumference. Materials and Methods: The study was conducted on 1000 Nepalese individuals in Manipal Teaching Hospital, Manipal College of Medical Sciences and surrounding locality after getting the ethical clearance. The age range for participants were between 30-60 years from both genders. The systolic and diastolic components of blood pressure (SBP, DBP) with and without the history of anti-hypertensive medication and the neck circumferences of the participants were taken in consideration. The data were analyzed with SPSS 20 version. Results: The male occupied $76.4 \%$ and the rest were female. The total mean of SBP and DBP were comparatively more in male $[123.24 \pm 11.11 \mathrm{mmHg} ; 83.08 \pm 8.24 \mathrm{mmHg}]$ than in female. The maximum numbers of participants taking anti hypertensive drugs [AHD] in male and female were age range between 35-44 and 45-54 respectively. The total mean of $\mathrm{NC}$ is more in male $(38.08 \pm 2.46 \mathrm{~cm})$ than in female. The $\mathrm{NC}$ had weak positive correlation with SBP and DBP. This correlation was more positive with DBP in female participants under medication which was statistically significant $(\mathrm{p}<0.05)$. Conclusions: The NC shows the positive correlation with the components of blood pressure. This correlation is comparatively more with DBP in female taking anti-hypertensive drugs.
\end{abstract}

Keywords: blood pressure; diastolic; neck circumference; systolic.

\section{INTRODUCTION}

Hypertension is one of the major health issues of this 21 st century. The sedentary lifestyle along with dietary modification plays important role for development of hypertension. This however doesn't exclude the stress in working or personal life related with modern civilization. Worldwide, about more than one billion people having the high blood pressure especially in developing countries. ${ }^{1}$

Long-term high blood pressure increase the risk of cardiovascular disease like coronary artery diseases, cardiac arrest, stroke, peripheral vascular disorder and also lead to vision loss, chronic kidney disorder and permanent dementia. ${ }^{2-3}$ Obesity is considered as one of the key factors for hypertension. But in case of the upper half of body, the deposition of the adipose tissue in neck indicates the initial stage of obesity. Therefore the measurement of the neck circumference is used to identify the initial stage of the obesity. ${ }^{4}$ It is considered as simple tool to measure overweight. ${ }^{5}$ The increase in neck circumference can also correlates positively with changes in systolic and diastolic blood pressure. ${ }^{6}$

Thus, the aim of this study is to identify size of the neck circumference and the relations between the components of blood pressures with neck circumference.

\section{MATERIALS AND METHODS}

The cross- sectional study was carried out in OPD patients of Manipal Teaching hospital, staffs of Manipal College of Medical Sciences and the local people of Pokhara in between June 2018 to August 2018 after getting the ethical clearance from the Institutional Review Committee -MEMG-IRC Ref1296. The participations were done after verbally informed consent. And the participants were between 30-60 years of age. The instrument sphygmomanometer and stethoscope were used for measuring the blood pressure and a non-elastic inch tape was used to measure the neck circumference. A total of 1000 subjects were enrolled in the study

Correspondence: Dr. Sarbada Makaju, Department of Anatomy, Manipal College of Medical Sciences, Pokhara, Kaski, Nepal. Email: sarbadamakaju@gmail.com. Phone: +977-9846119330. DOI: $10.3126 / j \mathrm{cmsn} . v 14 i 4.21114$. Article received: 2018-09-17. Article accepted: 2018-12-13. 
from both genders with equal distribution of participants taking anti-hypertensive drugs or not. The total number of the male and female were 764 and 236 respectively. Whereas, the total number of male and female with anti-hypertensive drugs were 399 and 101 respectively. The blood pressure was measured by the aneroid sphygmomanometer in right brachial artery following 80/40 rule. The participants were asked to sit comfortably for almost $10 \mathrm{~min}$ before the procedure. And blood pressure was measured two times with a 5-min rest interval between the measurements in a sitting position. In-order to measure the neck circumference, the inch tape was kept at the level of thyroid cartilage. Both the medicated and nonmedicated hypertensive people were taken. The data were entered in SPSS version 20. The descriptive statistics and the Pearson's correlation test were applied for analysis. The confidence interval of $95 \%$ was taken and the relation was considered statistically highly significant with $\mathrm{p}<0.001$ and statistically significant with $\mathrm{p}<0.05$.

\section{RESULTS}

The total number of participants was 1000 in which 764 and 236 were male and female respectively. The maximum total participants were in between 35-44 years (Figure 1). In both gender the mean of systolic blood pressure was highest in between 55 to 64 years and mean of diastolic blood pressure was highest in between 45 to 54 years. The highest

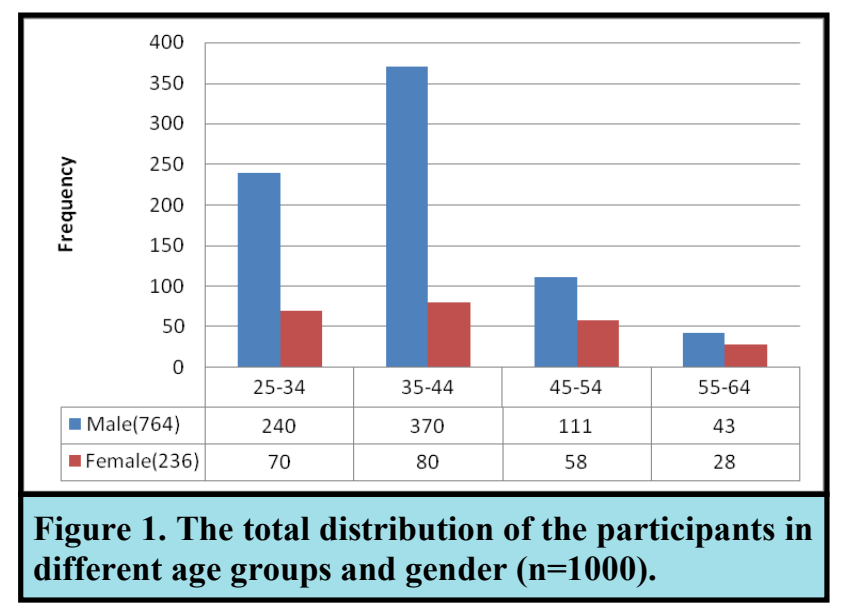

number of participants taking anti-hypertensive drugs in male and female were in 35-44 and 45-54 age group respectively (Table 1).The total mean of $\mathrm{NC}$ is greater in male than female. The male participants have the larger neck circumference in between 55-64 years and whereas in case of female it was in between 45-54 years (Table 2).

\begin{tabular}{|lll|}
\hline \multicolumn{3}{|c|}{ Table 2. Mean distribution of neck circumferences } \\
according to different age groups and gender.
\end{tabular}

The neck circumference had weak positive correlation with age in both gender (Figure 2).

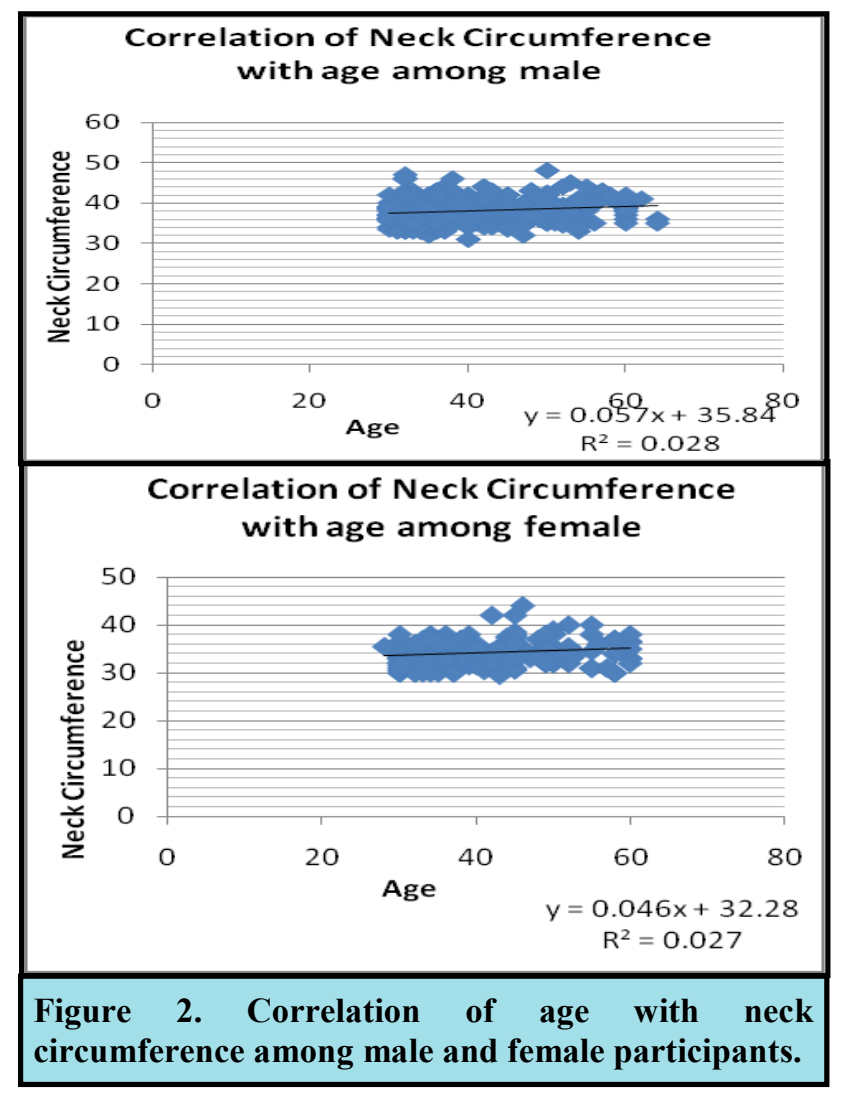

The overall mean of age, SBP, DBP and neck

\begin{tabular}{|c|c|c|c|c|c|c|c|c|}
\hline \multirow[t]{3}{*}{ Age groups } & \multicolumn{4}{|l|}{ Male } & \multicolumn{4}{|l|}{ Female } \\
\hline & \multicolumn{2}{|l|}{ Mean \pm SD of } & \multicolumn{2}{|c|}{ Medication } & \multicolumn{2}{|l|}{ Mean \pm SD of } & \multicolumn{2}{|c|}{ Medication } \\
\hline & SBP (mmHg) & DB (mmHg) & Yes (n) & No (n) & SBP (mmHg) & DB (mmHg) & Yes (n) & No (n) \\
\hline 25-34 & $121.01 \pm 9.80$ & $82.00 \pm 7.38$ & 67 & 173 & $114.00 \pm 0.10$ & $75.57 \pm 8.55$ & 16 & 54 \\
\hline $35-44$ & $122.39 \pm 9.75$ & $83.07 \pm 7.69$ & 232 & 138 & $116.40 \pm 9.14$ & $78.10 \pm 8.57$ & 32 & 48 \\
\hline $45-54$ & $127.39 \pm 0.12$ & $85.31 \pm 9.47$ & 71 & 40 & $128.07 \pm 0.13$ & $84.00 \pm 0.10$ & 33 & 24 \\
\hline $55-64$ & $132.40 \pm 0.16$ & $83.46 \pm 0.12$ & 29 & 14 & $129.57 \pm 0.17$ & $82.50 \pm 8.65$ & 20 & 9 \\
\hline Total & $123.24 \pm 11.11$ & $83.08 \pm 8.24$ & 399 & 365 & $120.11 \pm 13.63$ & $79.30 \pm 9.60$ & 101 & 135 \\
\hline
\end{tabular}


Makaju et al. Correlation of the Neck Circumference with Blood Pressure

circumference was greater in the participants with the history of anti-hypertensive drugs which was statistically highly significant $(\mathrm{p}<0.001)$ (Table 3 ).

\begin{tabular}{|lll|}
\hline $\begin{array}{l}\text { Table 3. Mean distribution of different variables in } \\
\text { total participants with and without the history of } \\
\text { anti-hypertensive drugs. }\end{array}$ \\
\hline \multicolumn{3}{|c|}{ Mean \pm SD } \\
\hline Variables & $\begin{array}{l}\text { Without } \\
\text { tion (500) }\end{array}$ & $\begin{array}{l}\text { With medication } \\
\text { (500) }\end{array}$ \\
Age(years) & $37.41 \pm 7.13$ & $41.59 \pm 7.78$ \\
SBP(mmHg) & $120.03 \pm 10.60$ & $124.98 \pm 12.45$ \\
DBP (mmHg) & $80.27 \pm 8.65$ & $84.11 \pm 8.37$ \\
$\begin{array}{l}\text { Neck circum- } \\
\text { ference(cm) }\end{array}$ & $36.75 \pm 2.90$ & $37.68 \pm 3.99$ \\
\hline
\end{tabular}

There was weak positive correlation of neck circumference with DBP and SBP in participants with anti-hypertensive drugs (Figure 3).

The correlation of neck circumference with SBP and DBP in participants with or without antihypertensive drugs showed positive result in female with anti-hypertensive drugs $(\mathrm{r}=0.54 ; 0.70)$ in age group 25-34 years which was statistically significant (Table 4 and Table 5).

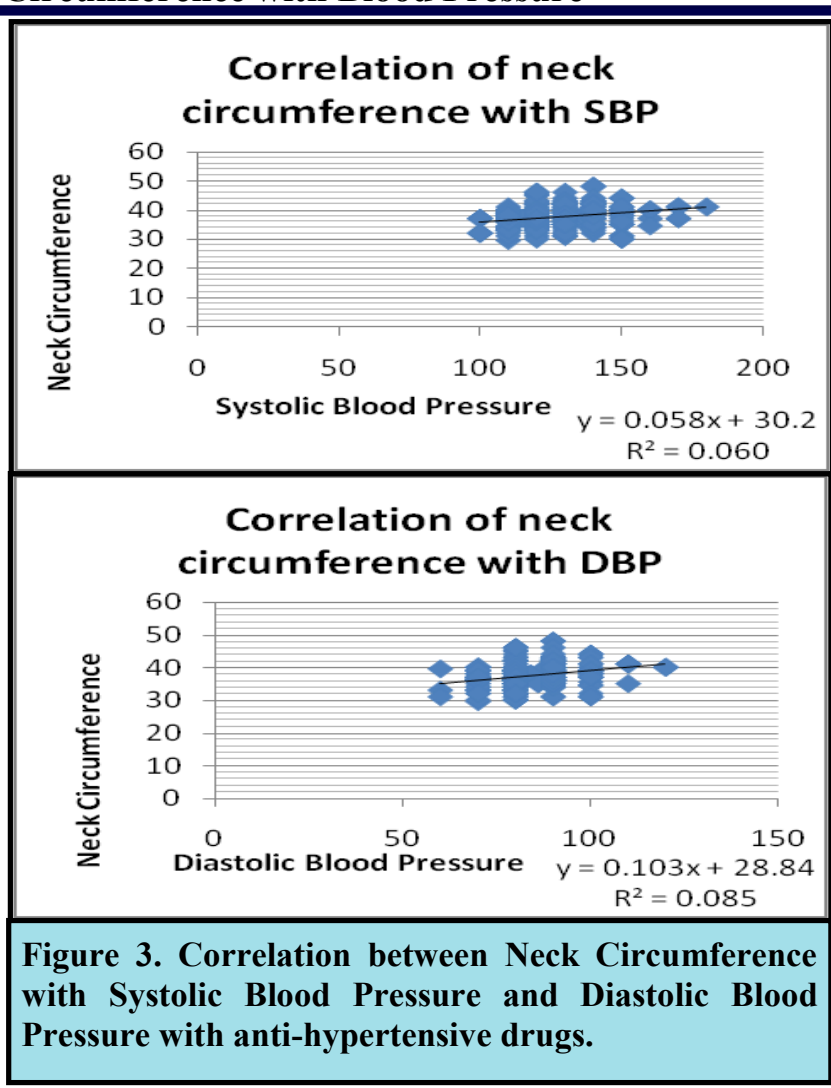

Table 4. Correlation of neck circumference with Systolic Blood Pressure within different age groups, gender and medication profile.

\begin{tabular}{|c|c|c|c|c|c|c|c|}
\hline \multirow{8}{*}{$\begin{array}{l}\text { Neck circum- } \\
\text { ference }\end{array}$} & \multirow[t]{4}{*}{ Age groups } & \multicolumn{6}{|c|}{ Systolic Blood Pressure } \\
\hline & & \multicolumn{2}{|c|}{ With Medication } & \multicolumn{2}{|c|}{ Without Medication } & \multicolumn{2}{|c|}{ In General } \\
\hline & & Male & Female & Male & Female & Male & Female \\
\hline & & $\mathbf{r}(\mathbf{p})$ & $\mathbf{r ( p )}$ & $\mathbf{r}(\mathbf{p})$ & $\mathbf{r ( p )}$ & $\mathbf{r ( p )}$ & $\mathbf{r ( p )}$ \\
\hline & $25-34$ & $\begin{array}{l}0.28 \\
(0.01)\end{array}$ & $\begin{array}{l}0.54 \\
(0.02)\end{array}$ & $\begin{array}{l}0.18 \\
(0.01)\end{array}$ & $\begin{array}{l}-0.00 \\
(0.95)\end{array}$ & $\begin{array}{l}0.22 \\
(0.00)\end{array}$ & $\begin{array}{l}0.16 \\
(0.16)\end{array}$ \\
\hline & $35-44$ & $\begin{array}{l}0.32 \\
(0.00)\end{array}$ & $\begin{array}{l}-0.13 \\
(0.46)\end{array}$ & $\begin{array}{l}0.11 \\
(0.19)\end{array}$ & $\begin{array}{l}0.17 \\
(0.22)\end{array}$ & $\begin{array}{l}0.23 \\
(0.00)\end{array}$ & $\begin{array}{l}-0.002 \\
(0.98)\end{array}$ \\
\hline & $45-54$ & $\begin{array}{l}0.40 \\
(0.00)\end{array}$ & $\begin{array}{l}0.00 \\
(0.99)\end{array}$ & $\begin{array}{l}0.03 \\
(0.82)\end{array}$ & $\begin{array}{l}0.21 \\
(0.30)\end{array}$ & $\begin{array}{l}0.31 \\
(0.001)\end{array}$ & $\begin{array}{l}0.10 \\
(0.41)\end{array}$ \\
\hline & $55-64$ & $\begin{array}{l}0.23 \\
(0.24)\end{array}$ & $\begin{array}{l}-0.2 \\
(0.35)\end{array}$ & $\begin{array}{l}-0.57 \\
(0.03)\end{array}$ & $\begin{array}{l}0.38 \\
(0.34)\end{array}$ & $\begin{array}{l}0.13 \\
(0.38)\end{array}$ & $\begin{array}{l}-0.26 \\
(0.16)\end{array}$ \\
\hline
\end{tabular}

Table 5. Correlation of neck circumference with Diastolic Blood Pressure within different age groups, gender and medication profile.

\begin{tabular}{|c|c|c|c|c|c|c|c|}
\hline \multirow{8}{*}{ Neck circumference } & \multirow{4}{*}{$\begin{array}{l}\text { Age } \\
\text { groups }\end{array}$} & \multicolumn{6}{|c|}{ Diastolic Blood Pressure } \\
\hline & & \multicolumn{2}{|c|}{ With Medication } & \multicolumn{2}{|c|}{ Without Medication } & \multicolumn{2}{|c|}{ In General } \\
\hline & & Male & Female & Male & Female & Male & Female \\
\hline & & $\mathbf{r ( p )}$ & $\mathbf{r ( p )}$ & $\mathbf{r}(\mathbf{p})$ & $\mathbf{r}(\mathbf{p})$ & $\mathbf{r ( p )}$ & $\mathbf{r ( p )}$ \\
\hline & $25-34$ & $0.37(0.00)$ & $0.70(0.00)$ & $0.30(0.00)$ & $0.04(0.75)$ & $\begin{array}{l}0.33 \\
(0.00)\end{array}$ & $\begin{array}{l}0.21 \\
(0.07)\end{array}$ \\
\hline & $35-44$ & $0.28(0.00)$ & $0.05(0.78)$ & $0.03(0.67)$ & $0.34(0.01)$ & $\begin{array}{l}0.17 \\
(0.001)\end{array}$ & $\begin{array}{l}0.17 \\
(0.12)\end{array}$ \\
\hline & $45-54$ & $0.22(0.06)$ & $0.23(0.19)$ & $0.29(0.06)$ & $-0.18(0.40)$ & $\begin{array}{l}0.24 \\
(0.01)\end{array}$ & $\begin{array}{l}0.15 \\
(0.24)\end{array}$ \\
\hline & $55-64$ & $0.36(0.06)$ & $0.12(0.60)$ & $-0.37(0.18)$ & $0.10(0.80)$ & $\begin{array}{l}0.167 \\
(0.28)\end{array}$ & $\begin{array}{l}0.018 \\
(0.927)\end{array}$ \\
\hline
\end{tabular}




\section{DISCUSSION}

In this study the male participants had maximum mean of systolic blood pressure, diastolic blood pressure and neck circumference. The components of blood pressure also started to increase with age which can be related with age related vascular changes and autonomic dominance. Similarly, as the age increases the size of the neck circumferences also increases. It has been stated that men with neck circumference lesser than 37 $\mathrm{cm}$ and women with lesser than $34 \mathrm{~cm}$ are not considered as overweight. ${ }^{7}$ Neck obesity term is given when the neck circumference is $\geq 41 \mathrm{~cm}$ in men and $\geq 35 \mathrm{~cm}$ in women. ${ }^{8}$ The neck circumference in both the gender increases as the age increased. This also stated that as the age increases the collection of the adipose tissue increases. The amount of the adipose tissue increases that means more chances of vascular disorder. The results in this study also prove that the neck circumference can be used as an index for the upper body adipose tissue distribution. In clinically, it will provokes vascular endothelial injury. ${ }^{9}$

This study overall concludes that the SBP and DBP have positive correlation with neck circumference in female and male. This also prove with the statement made by some authors that it play a very important role in the development of hypertension. ${ }^{10}$ This correlates with the finding that neck circumferences are significantly associated with arterial BP and hypertension. ${ }^{11}$ Whereas, some authors also claimed that the increase in the neck circumference is the best indicator for hypertension in men with statistically highly significance. ${ }^{12}$

This result would have been more impactful with biochemical analysis of lipid profile for correlating the increase in serum lipid content with the increase in the diameter of neck circumference. Similarly the inclusion of the personal history related with ethnicity, drinking and smoking habits could increase the horizon of various etiological factors related with hypertension and increased neck circumference. The equal number of participation of female in this study would have made the result more valid.

\section{CONCLUSIONS}

The components of blood pressure increase with increase in the neck circumference. This correlation is comparatively more with DBP in female taking anti-hypertensive drugs. However, the mean of $\mathrm{NC}$, SBP and DBP are comparatively greater in male which increase with age .

\section{REFERENCES}

1. Appel L et al. Hypertension. J Am Heart Assoc. 2006;47(2):296-308

2. Lawes CM, Vander Hoorn S, Rodgers A. Global burden of blood-pressure-related disease, 2001. Lancet. 2008 May 3;371 (9623):1513-8

3. LacklandDT,Weber MA .Global burden of cardiovascular disease and stroke: hypertension at the core. Can J Cardiol. 2015;31(5):569-71.

4. Niniya $J$ et al. Neck circumference: a potential anthropometric marker for screening of hypertension in adult population of central India. Int $\mathrm{J}$ Community Med Public Health. 2016;3(12):3374-79.

5. Ozkaya I, Tunckale A. Neck Circumference Positively Related with Central Obesity and Overweight in Turkish University Students: A Preliminary Study.Cent Eur J Public Health. 2016 Jun;24(2):91-4.

6. Ben NL, Laor A. Relationship between changes in neck circumference and changes in blood pressure. Am J Hypertens. 2004;17:409-14.

7. Ben NL, Sohar E, Laor A. Neck circumference

as a simple screening measure for identifying overweight and obese patients. Obes Res. 2001;9(8):470-7.

8. Jose A et al. Relationship between neck circumference and hypertension in the National Hypertension Registry (the RENATA study). Rev Argent Cardiol.2012;80:275-79.

9. Piro S, Spampinato D, Spadaro L, Oliveri CE, Purrello F, Rabuazzo AM. Direct apoptotic effects of free fatty acids on human endothelial cells. Nutr Metab Cardiovasc Dis. 2008;18:96104.

10. Stojiljkovic MP, Zhang D, Lopes HF, Lee CG, Goodfriend TL, Egan BM. Hemodynamic effects of lipids in humans. Am J Physiol Regul Integr Comp Physiol. 2001;280:R1674-R1679.

11. Fan $\mathrm{S}$ et al. Neck circumference associated with arterial blood pressures and hypertension: A cross-sectional community-based study in northern Han Chinese.Sci Rep. 2017;7(1):2620.

12. Bum JL, Jong YK. A Comparison of the Predictive Power of Anthropometric Indices for Hypertension and Hypotension Risk. PLoS One. 2014;9(1):84897.

Citation: Makaju S, Chaudhary S, Alam M. . Correlation of the Neck Circumference with Blood Pressure. JCMS Nepal. 2018;14(4):209-12. 